\title{
A Bíblia em Mangá: perspectiva tillichiana sobre a nona arte
}

\author{
Leonardo Gonçalves de Alvarenga* \\ Nataniel dos Santos Gomes** \\ Monique Mattos Azevedo Alvarenga*** \\ Fernando Caminada Sabra****
}

\begin{abstract}
RESUMO
Este artigo faz uma transposição das análises de Paul Tillich para a nona arte. As escolhas de Tillich orientam-se, de preferência, para a cultura erudita, ao invés da cultura de massa, o kitsch. Mas dos tempos de Tillich até hoje a arte ganhou novas formas e reconhecimentos. As HQs estão nesta lista. Especificamente trouxemos o Mangá, que faz parte da cultura japonesa e possui traços muito peculiares. Dentre os temas abordados, o Mangá tem sido uma ferramenta de comunicação de elementos religiosos cristãos. O objetivo, portanto, é, a partir dos níveis de relação entre arte e religião elaborados por Paul Tillich fazer uma análise da Bíblia em Mangá, da série NEXT, publicada no Brasil em 5 volumes.

Palavras-chave: mangá; Paul Tillich; Bíblia; arte.
\end{abstract}

THE MANGA BIBLE: A TILLICHIAN PERSPECTIVE ON THE NINTH ART

\begin{abstract}
This paper transposes Paul Tillich's analysis to the ninth art. Tillich's choices are preferably oriented towards high culture rather than mass culture, a.k.a kitsch. From Tillich time to today, art has gained new forms and recognition. Comic Books are on this list. Specifically, Manga, which
\end{abstract}

* UEMS. Licenciatura em Filosofia (Claretiano). Doutor em Ciência da Religião (PUC-SP). Membro do Crelig e do NuPEQ. E-mail: alvarengalg2@gmail.com.

** UEMS. Licenciatura em Letras (UERJ). Doutor em Linguística (UFRJ). Coordenador e membro do NuPEQ. E-mail: natanielgomes@gmail.com.

*** UEMS. Licenciatura em Pedagogia (UERJ). Mestrando em Letras (UEMS). E-mail: niquemattos@hotmail.com.

**** UEMS. Licenciatura em Letras (UCDB). Mestre em Teologia (FABAPAR-PR) e mestrando em Letras (UEMS). Membro do NuPEQ. E-mail: revfernandosabra@gmail.com. 
is part of Japanese culture and has very peculiar traits. Among the topics covered, manga has been a communication tool for Christian religious elements. The objective, therefore, is, from the levels of relationship between art and religion elaborated by Paul Tillich, to make an analysis of the Bible in Mangá, from the NEXT series, published in Brazil in 5 volumes.

Keywords: Manga; Paul Tillich; Bible; Art.

\section{Introdução:}

Este texto, escrito a quatro mãos, é um endosso às possibilidades de abordagem em Paul Tillich, tomando como base a relação entre religião e arte. Ainda que Tillich não mostrasse interesse na cultura de massa e apreciasse as artes eruditas, do tempo em que escreveu até os dias de hoje a arte da vida cotidiana, kitsch, alcançou novos patamares e despertou interesse tanto de leigos quanto da academia. $\mathrm{O}$ artigo se propõe a uma análise dos quadrinhos Mangá, especificamente da série NEXT Mangá lançada no Brasil em 5 volumes, que traz as histórias bíblicas na cultura japonesa.

A relação entre arte e religião possui para Paul Tillich alguns níveis, sobre os quais chamaremos atenção e serão utilizados para análise do conteúdo da série NEXT Mangá. Essas categorias são: Estilo não religioso e tema não religioso; Estilo religioso e tema não religioso; Tema religioso e estilo não religioso; Estilo religioso e tema religioso. Como o conteúdo da obra analisada é grande, fizemos alguns recortes com imagens de alguns volumes. No texto também contextualizamos a arte do Mangá e a instrumentalização do mesmo para difusão da cultura cristã.

\section{Tema e estilo religioso da série NEXT Mangá}

Paul Tillich em sua teologia da cultura tinha enorme apreciação pelas artes auditivas, como por exemplo, a música de Bach, todavia sua preferência estava nas artes visuais, especialmente na pintura. Duas obras de arte lhe causaram especial impacto e, embora fossem de épocas diferentes, frequentemente fazia referência a elas. A primeira é Guernica, de Pablo Picasso (1937), que retrata a guerra civil espanhola. A segunda, é Madonna and Child with Singing Angels, de 
Sandro Botticelli (1477). Guernica teve sua importância devido à manifestação da realidade da condição humana, da tragédia da destruição, horror e absurdo da guerra e da própria vida, chegando a, na opinião de Tillich, ser considerada a mais importante obra de arte protestante contemporânea. Quanto a Madonna de Botticelli, ao contemplá-la no Museu Kaiser Friederich, em Berlim, teve um ato de revelação, Tillich declara: "Aquele momento afetou toda minha vida, deu-me as chaves para a interpretação da existência humana, trouxe vitalidade e verdade espiritual. Eu o comparo com o que é usualmente chamado de revelação na linguagem religiosa" (TILLICH apud CALVANI, 2005, p.53).

Para Tillich, aquele momento de revelação possibilitou a aparição de um aspecto do fundamento divino de todas as coisas. Isto, na sua interpretação, configura uma experiência religiosa, uma relação com o sagrado que vai além da experiência de qualquer realidade do cotidiano. A argumentação de Tillich sobre arte, exposto na série de Palestras Art and Society, declara que o ser humano é finito e, ao mesmo tempo em que é consciente desta finitude também é consciente de pertencer ao infinito, e isto produz angústia. Desta forma, o homem não está excluído somente do infinito ao qual pertence: também é excluído de todas as coisas finitas que não são ele mesmo e, por isso busca participar de outros seres. A maneira de penetrar na qualidade oculta das coisas que pertencem à esfera de cognição é a criação artística. A arte tem a capacidade de tornar o homem consciente de algo que, de outro modo, não atingiria. Sendo assim, a arte pode ser tanto criação como descoberta e, é uma das formas pelas quais o ser humano é capaz de transcender sua finitude. Eis o milagre da arte no pensamento de Tillich: descobrir algo extraordinário e mostrar o que descobriu em formas extraídas da realidade ordinária, comum, mas ao mesmo tempo apontando para além delas mesmas, para a "Realidade Última" (CALVANI, 1998, p.80).

Para Tillich, as funções básicas de toda arte são: expressão, transformação e antecipação. A arte expressa, por exemplo, o temor do ser humano diante das novas realidades que descobre ou o impacto sobre elas; a arte transforma realidades ordinárias de modo a que expressem o poder de algo além delas mesmas; e a arte antecipa possibilidades de ser que transcendem as possibilidades já dadas (TILLICH apud CALVANI, 2005). 
Foi o expressionismo o estilo artístico que, segundo Tillich melhor realizou estas funções da arte. Como movimento de vanguarda, entre os anos de 1910 e 1927, absorveu diversas tendências modernas com o objetivo de renovar a pintura. O expressionismo também pode ser percebido em outras formas de arte caracterizadas pela tensão, pela descrição hiperbólica de estados extremos de êxtase e desespero. No teatro, por exemplo, a peça A Estrada de Damasco, de Strindberg, foi considerada por Furness como o início do drama expressionista. $\mathrm{Na}$ poesia, que ressalta a revelação do significado último do mundo, aquele além das aparências, destacam-se Georg Trakl e Ernst Stadler.

Quanto a nona arte e mais especificamente o mangá, que são os quadrinhos japoneses, esta não é a primeira vez que Paul Tillich é utilizado como chave de leitura para compreensão das HQs (CALDAS, 2017; 2018; MACHADO, 2018; REBLIN, 2012, SOLDATI REIS, 2019) e provavelmente não será a última. Certamente, as escolhas de Tillich orientam-se, de preferência, para a cultura erudita, ao invés da cultura de massa, da vida cotidiana, o kitsch. Mas de Tillich aos dias atuais muita coisa mudou, inclusive a literatura e mais especificamente as HQs.

Na Feira do Livro de Frankfurt, na Alemanha, o maior evento do mercado editorial, em 2000, foi dado o destaque à HQ, recebendo não só um Hall especial como também a declaração: "Quadrinhos são reconhecidos como Literatura! HQ é Arte!"1. "As histórias em quadrinhos cruzam a linha entre a alta cultura e a cultura de massa" (ABRÃO; GOMES, 2014). Além disso, essa literatura / arte se desenvolveu "ao largo e no interior das produções das outras artes, desde obras e personagens criados para o mundo infantil até a citação e o trabalho produzido com o cânone literário e filosófico dos mundos ocidental e oriental" (ABRÃO; GOMES, 2014). Deste modo empreenderemos um esforço em analisar a nona arte, especificamente o mangá da série Next sob uma perspectiva tillichiana. Umas das características do pensamento de Paul Tillich é a abertura ao diálogo e o pensar nas fronteiras (boundaries).

Em se tratando dos níveis de relação entre arte e religião, Tillich estabeleceu quatro categorias na interminável busca de definir a presença religiosa das criações artísticas: Estilo não religioso e tema não

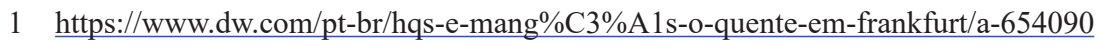


religioso; Estilo religioso e tema não religioso; Tema religioso e estilo não religioso; Estilo religioso e tema religioso (DA SILVA, 2008).

a) Estilo não religioso e tema não religioso - descrita também como "arte secular". Neste caso a preocupação última é indiretamente expressa. Os assuntos preferidos são naturezas mortas, histórias de desilusões amorosas, paisagens etc. Nesta categoria Tillich destaca que a arte deve revelar aspectos da vida não acessíveis às experiências do cotidiano. Não há estilo religioso, nem tema, mas esse é um aspecto do princípio protestante: Deus está presente na existência secular tanto quanto na existência sagrada (...) Num estilo secular, sem tema religioso, o poder de ser é visível não direta, mas indiretamente.

b) Estilo religioso e tema não religioso - Nesta categoria onde estão ausentes do tema as cenas bíblicas ou afirmações da fé, estão presentes assuntos do cotidiano impregnados de poder religioso. Para exemplificar, Tillich utiliza a Night Café, onde Van Gogh representa o horror do vazio, uma sensível descrição da sociedade humana com suas vacuidades, nulidade e futilidade: um garçom à esquerda, um homem sentado à direita e o centro vazio.

c) Tema religioso e estilo não religioso - Embora seja sobre temas religiosos, o estilo não o é por ser extremamente superficial. Para Tillich as artes religiosas devem expressar algo de Deus e das estruturas básicas pelas quais ele cria a realidade, e não meros sentimentalismos. Sendo assim, elas são perigosamente irreligiosas, porque banalizam o sagrado.

d) Tema religioso e estilo religioso. Nesta relação ocorre uma união, que no sentido mais concreto pode ser chamada de arte religiosa, porquanto estilo e conteúdo concordam. Esta forma é geralmente chamada expressionista, porque esta é uma configuração em que a superfície é rompida para expressar algo. Estabelece-se assim, um gradiente segundo o qual as obras mais completas, por assim dizer, seriam as que manifestam conjuntamente "tema e estilo religiosos". Este é o caso já mencionado da Madonna de Bottticelli, em que Tillich foi tomado por um estado muito próximo do êxtase. 
Esses quatro elementos possuem uma descrição detalhada do que se poderia encontrar na arte. No caso do último, ainda que se caracterize por ser uma obra completa, o tema não é determinante para qualificar a importância religiosa de uma arte. Para Tillich, "o que mais pesa é o "estilo", ou seja, o poder que a arte tem de expressar com vitalidade, coragem e originalidade, o tema proposto". Resumindo, o tema não caracteriza uma arte como religiosa, "mas sim o estilo e o conteúdo substancial inconscientemente presente numa cultura, num grupo e num indivíduo, dando a paixão e o poder diretivo àquele que cria, bem como o significado e o poder de sentido a suas criações" (CALVANI, 2005, p.45).

Ao conjecturarmos sobre a possibilidade de Paul Tillich apreciar/avaliar a série Next Mangá enquanto arte, ainda que de massa e de pouca afeição ao gosto pessoal do teólogo, podemos chegar à hipótese de que a série possui tema não religioso e estilo religioso. $\mathrm{O}$ que certamente poderia provocar em Tillich um olhar mais atento à obra. Ela tem objetivos missionários e nesse aspecto possivelmente encontraria algum tipo de resistência ou empoeiramento nas lentes do autor, dependendo do entendimento acerca de missão, uma vez que a arte em questão não expressa apenas uma preocupação última, mas quer impor esse olhar enquadrando o leitor, não permitindo o estado livre de percepção e deslumbramento. Por outro lado, são favoráveis as aparências estéticas e de beleza própria de uma cultura que destoam do tema religioso ainda que o queiram expressar. A recepção do texto bíblico, que carrega em si a mensagem, traz em uma nova situação um impacto no leitor.

Os referenciais explícitos na série, dados pelo próprio artista ao batizar sua criação, não apresentam o tema religioso. A partir de então, quem for apreciar essa obra de arte, ou mais especificamente se interessar, comprar e ler os fará com um certo condicionamento ao gênero mangá.

\section{Bíblia, literatura, representação iconográfica e mangá}

A Bíblia ocupa um lugar de destaque na literatura ocidental. As traduções para o latim e o grego e a sua utilização na catequese, na liturgia e como inspiração artística para as igrejas grega e latina consolidaram o legado destas duas línguas na cristandade oriental e ocidental. 
Desde o período de exílio dos judeus na Babilônia e na Pérsia nasceu a primeira tradução dos escritos sagrados judaicos, o Antigo Testamento para os cristãos, para o aramaico, chamada de peshita. Devido à forte aculturação dos judeus e a perda do hebraico como língua comum, a peshita, mesclando tradução literal e paráfrases explicativas, dá início às traduções que ocorreriam em períodos posteriores. Posteriormente, a Septuaginta, a tradução para o grego dos textos sagrados dos judeus, realizou o mesmo papel, mas para o mundo em que o grego era língua comum (TREBOLLE, 1993).

Nesse sentido, o cristianismo seguiu o judaísmo, devido à origem comum, traduzindo para o armênio, georgiano, entre outras línguas (TREBOLLE,1993), confirmando a importância dada à palavra escrita na cultura cristã em continuidade à tradição judaica, pois em ambos os casos a revelação se dá pela palavra, a Escritura é a Palavra de Deus. Assim, as traduções cumpriram o seu papel litúrgico, catequético e estético, pois a influência do texto bíblico e suas teologias não ficaram restritas a palavra escrita, ao verbal.

Frye (2004) expõe a influência que as Escrituras Sagradas judaico-cristãs exerceram sobre a literatura ocidental, e, no caso avaliado por ele, a literatura anglo-saxã. Harold Bloom e Robert Alter também podem ser citados como professores de literatura que, mesmo não se colocando como religiosos, reconhecem o valor literário da Bíblia, como obra a ser considerada como legado cultural da humanidade. Ambos escreveram sobre o texto bíblico, mas a partir de diferentes perspectivas. Alter (2007) produziu uma obra analítica sobre as narrativas bíblicas e Bloom (2013), sobre o texto de crítica literária. Os autores citados abriram caminho para outras obras em que a Bíblia é estudada a partir dos cânones literários.

A representação iconográfica desta literatura também pode ser constatada desde muito cedo. As catacumbas romanas, por exemplo, possuem uma grande quantidade de registros iconográficos catalogados, documentados (HUSKINSON, 1982), e a Via-crúcis Sacra, representação dos últimos acontecimentos da vida de Jesus a caminho da cruz, a partir do século XV (KRAFT apud RODRIGUES, 2013), deve ser destacada na tradição cristã ocidental devido a sua ampla aceitação e registro, considerando que se tornou presença frequente nos templos 
católicos. A Via Sacra e as demais representações iconográficas religiosas confirmam o seu papel na devoção pessoal, na catequese e na estética de templos, ainda que primitivos.

O cristianismo, apesar do pouco destaque que esta informação recebe, é uma religião que nasce no chamado Oriente Próximo, Oriente Médio. Nasce no entroncamento entre Ocidente e Oriente, ganhando, inicialmente, maior presença nas cidades da antiga província romana da Síria, atual Turquia e Síria, e avança em direção ao Oriente seguindo a rota da seda e alcançado lugares e povos pouco associados ao cristianismo.

A exemplo do que ocorreu no ocidente cristão, a representação iconográfica acompanhou o cristianismo em direção ao oriente assimilando a estética de cada região e povos criando um delicado e belo painel artístico-religioso. Quatro das tradições cristãs mais importantes contribuíram para a composição deste painel no oriente, a igreja ortodoxa de língua grega, a igreja síria e a igreja nestoriana, estas de língua siríaca e o catolicismo romano, de tradição latina, que será responsável pela presença cristã no Japão a partir do século XVI.

Para entender essas cenas, vale destacar que a região da Capadócia, atual Turquia, possui representações iconográficas em um conjunto de cavernas que reproduzem diversos ícones cristãos. Como afirmado desde o início, as imagens adotam formas e estilo local para a elaboração de ícones de caráter litúrgico, sobretudo.

Conforme dito anteriormente, a rota da seda como caminho de propagação da fé cristã e da sua iconografia tem início desde muito cedo. A cidade de Antioquia, importante centro cristão desde o primeiro século, é ponto de chegada e partida para as caravanas comerciais que levavam mercadorias e cristãos que expandiam as fronteiras do conhecimento de sua fé que foi propagada até a China. O número de representações é significativo e variado, dois autores podem ser citados como ilustração da riqueza do pensamento e da iconografia produzidos, Baumer (2006) e Palmer (2001). Por intermédio dos nestorianos, a fé cristã e suas representações chegaram aos atuais Iraque, Irã, Índia, Mongólia, Turquestão, Tibet e China. (BAUMER,2006). Pensando no contexto do cristianismo na China, ela é o ponto de chegada no percurso, trajetória missionária nestoriana. Os missionários tiveram atestada 
a sua presença por meio do registro contido na Estela de Xi'na (781 d.C.), que narra como Taizong (629-649 d.C.), segundo imperador da dinastia Tang (618-907 d.C.), região central da China, reconheceu a fé nestoriana, que teve em Alopen seu primeiro missionário, autorizando a ordenação e a construção do primeiro templo cristão em território chinês de monges e construção de um templo, que ficou conhecido como Pagode de Daqin, devido a sua arquitetura seguir a tradicional construção chinesa, (PIERROTI, 2015; PALMER, 2001).

As representações abaixo são reconhecidas como cristãs e apresentadas como ícones nestorianos produzidos na China, encontradas no templo nestoriano de Qocho, no período abordado:

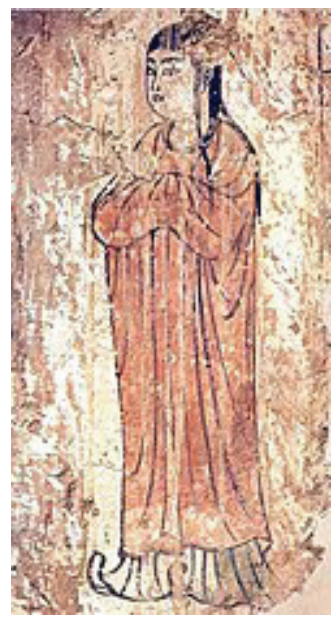

A Mulher Contrita

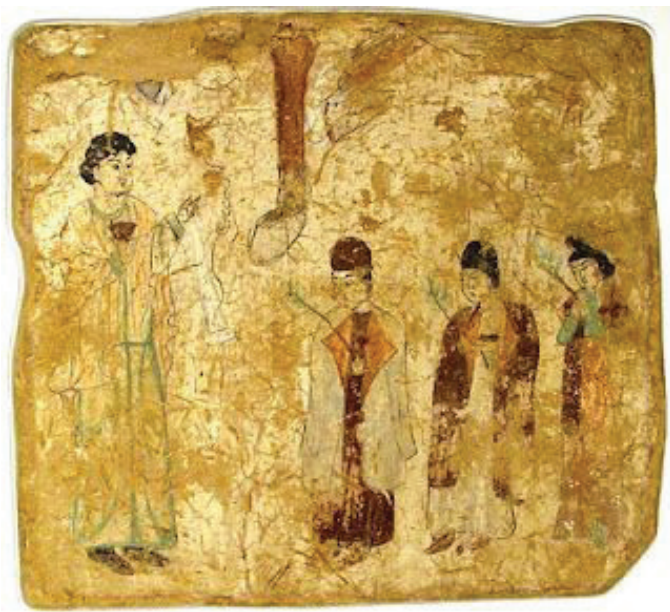

Procissão do Domingo de Ramos

(PIERROTI, 2015, p. 83)

\section{Figura 1}

O texto precedente teria sua pouca importância em sua proposta de promover uma aproximação entre a Bíblia e o mangá, se não fosse pela descoberta do rolo cristão do Museu Sawada Miki Kinenkan, na cidade de Oiso, datado de 1592, fato comunicado pela direção do museu em uma conferência de imprensa. O rolo, que estava guardado no museu sem ter o valor reconhecido, faz parte da coleção do museu em que relíquias do cristianismo japonês estão em exposição. 
O rolo de 320 centímetros de comprimento por 22 centímetros de largura, de papel tradicional japonês washi, pintado com tinta preta sumi, possui 15 figuras pintadas da direita para a esquerda, de acordo com a escrita japonesa, terminando com orações latinas, de conteúdo não divulgado, transcritas para caracteres japoneses.

O estudioso do museu de História de Yokohama, Osamu Inoue, avaliou o documento constatando a sua relação com o período histórico da data, o que corresponde ao teste realizado com carbono 14, que atribuiu data de produção do papel a um período anterior a 1633. Este período corresponde ao momento histórico em que o cristianismo era tolerado, o que mudou com a sua proibição e banimento em 1614.

As quinze figuras compõem uma narrativa pictórica coerente, também nominada de desenhos, partindo da anunciação do nascimento de Jesus até a entronização de Maria, o que corresponde aos mistérios do rosário como era rezado na época. Os mistérios são os seguintes: Mistérios Gozosos, Mistérios Dolorosos e Mistérios Gloriosos. Os personagens estão adaptados a cultura japonesa por intermédio do uso das vestimentas tradicionais, traços pessoais e elementos que identificam a cultura japonesa.

O mais importante sobre este rolo em sua relação com o mangá é que ele corresponde ao chamado Emaki-Mono. Tipo de desenho sequencial que foi introduzido no Japão por meio de monges budistas oriundos da China que apresentavam os mistérios do Buda através dos desenhos feitos em disposição sequencial.

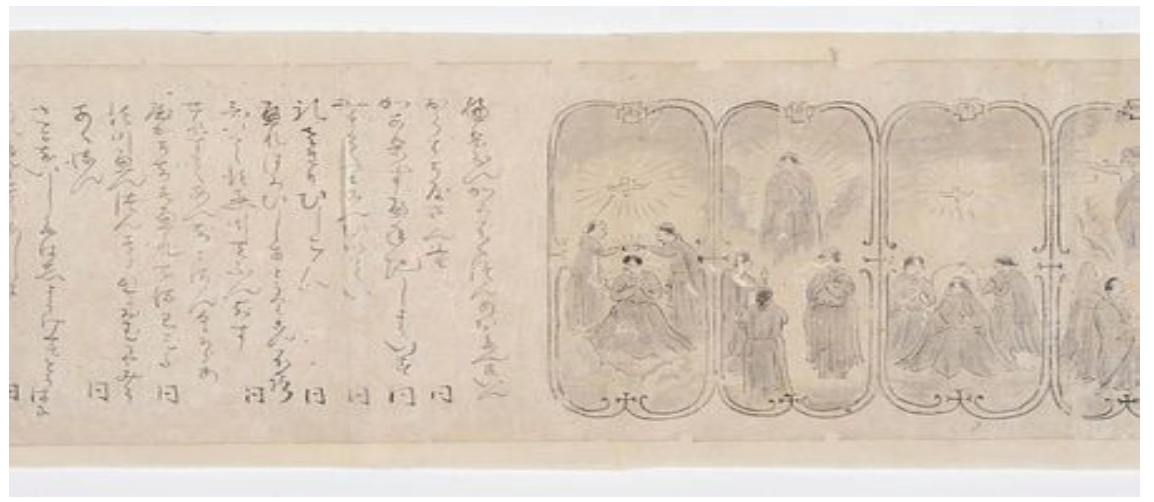

Figura 2

Fonte: Nippon.com (Copyright The Jiji Press, Ltd), 2018. 
A transposição inclui a forma, o modo, material, propósito religioso, e toda uma incorporação cultural que reproduzem, criam e recriam. Assim, a prova mais documentada da presença missionária cristã no Japão, por meio dos jesuítas, faz uso, a exemplo das missões nestorianas, de elementos culturais para a composição dos seus ícones, mas no caso deste rolo, houve uma elaboração completa a partir de uma prática cultural que se assemelha a arte sequencial e por outros é considerada a precursora do mangá. Logo, é importante destacar que o mangá, a conhecida arte sequencial japonesa, possui a sua pré-história ligada ao Emaki-mono, a exposição acima revela esta relação. Embora haja quem afirme a existência do mangá em datas muito remotas, a expressão surge em 1814 Hokusai Manga, por meio de Katsushika Hokusai, que criou, em quinze volumes, encadernados, uma serie de ilustrações sem conexão, mas a palavra mangá foi cunhada nesse contexto.

Rakute Kitazawa, em 1905, cria a sua primeira revista, e influenciou gerações de desenhistas. A partir de 1947, Osamu Tezuka, que reconhecia a influência de Kitazawa, publica Shintaka Rajima e concebe o mangá como o conhecemos atualmente. A expansão de temas e técnicas conduziu o mangá para diversas temáticas específicas, inclusive a religiosa, que inicialmente abordou, naturalmente, as religiões japonesas.

A breve narrativa proposta neste seguimento, apresenta, sinteticamente, como a iconografia religiosa cristã se manifestou desde o seu início como elemento de divulgação, de devoção e produção cultural estética. Das catacumbas romanas a cultura pop dos mangás alcançando grupos em todos os continentes, tornando-se cultura de massa.

A abordagem realizada, até o momento, buscou estabelecer uma aproximação histórica da representação iconográfica inspirada pela literatura cristã e de como isso ocorreu em um movimento geográfico que se originou no Oriente Médio e se dirigiu ao oriente, alcançando a China e o Japão.

O mangá, arte nipônica correlacionada às Histórias em Quadrinhos (HQs) ocidentais, realizou o movimento inverso. A partir do oriente se disseminou e, através de seus traços característicos, representou a cultura japonesa e suas influências em um amplo espectro de histórias, mitologias, heróis e religião. A arte do mangá não se limitou a criar a partir do seu contexto oriental, recriou outras importantes obras da 
cultura universal e a Bíblia foi contemplada por alguns projetos, dentre eles, o projeto NEXT.

\section{Série NEXT Mangá: panorama e análise}

A série criada pela NEXT mangá e escrita por Ryo Azumi e Kelly Shinozawa tem objetivos missionários de levar a história bíblica completa para leitores de todo o mundo. Desde o lançamento, já foram vendidos e distribuídos quase 10 milhões de livros e livretos em 40 idiomas. Os mangás foram traduzidos para várias línguas e no Brasil a primeira edição é de 2010 em parceria com a Editora Vida Nova.

Os títulos da série são: Mangá Messias, Mangá Metamorfose, Mangá Motim, Mangá Mélek e Mangá Mensageiros. Mangá Motim começa com a rebelião de Satanás no céu até o êxodo. Mangá Mélek continua com a rebelião do povo de Israel no deserto até o reinado de Salomão. Mangá Mensageiros começa do reinado de Salomão até o cativeiro do povo de Israel. Mangá Messias retrata a vida de Jesus, do nascimento à crucificação. Mangá Metamorfose começa com a descida do Espírito Santo e o crescimento da igreja primitiva.

Sem abandonar a qualidade na elaboração da releitura das narrativas, conseguem despertar o leitor para um novo modo de perceber a teologia contida na série. A linguagem não verbal pretende produzir significações por intermédio das imagens, em que os personagens bíblicos ganham aparência estética e a beleza é considerada e retratada a fim de produzir impacto no leitor. Por ser um projeto de alcance mundial, permite, a leitores de todos os continentes e, consequentemente, raças e religiões, conhecerem aspectos teológicos judaico-cristãos via outro código semiótico.

A obra elaborada por um grupo de quadrinhistas japoneses recria a narrativa bíblica a partir da arte do mangá. A originalidade da obra não está na utilização do gênero mangá para retratar a narrativa bíblica, mas no fato de recriar esta narrativa reunindo os textos de um mesmo contexto histórico, os textos proféticos estão juntos aos textos dos reis, por exemplo, permitindo e provocando uma nova recepção do texto bíblico.

A recriação japonesa editada em cinco volumes selecionou os textos majoritariamente narrativos, abrangendo, de acordo com o cânon 
ocidental cristão, os cinco livros da lei de Moisés, os livros históricos e os proféticos, que neste caso foram reelaborados harmonicamente aos livros de Reis, onde os profetas foram colocados em seu momento histórico. Os dois últimos volumes, evangelhos e o livro dos Atos, também de conteúdo narrativo, concluem o arco narrativo onde o volume sobre o Messias recria a história de Jesus reunindo os quatro evangelhos, Mateus, Marcos, Lucas e João, em um episódio que inicia com o nascimento e termina com o comissionamento a todas as nações.

Deve ser destacado que a reunião de textos não é um acontecimento estranho à fé cristã. Orígenes, em sua Hexapla, dispôs textos de diferentes línguas em colunas proporcionando uma leitura comparada do Antigo Testamento. A harmonia entre os evangelhos também foi proposta, neste caso, em o Diatessaron de Tatiano tem-se um exemplo. A recriação compõe de modo vivo e criativo a relação de textos que estão separados na apresentação canônica tradicional, mas que são reunidos em uma única narrativa sequencial produzindo um novo texto.

Lançando o olhar especificamente sobre o Mangá Messias, quarto volume da série, considerando o que foi apresentado acima, a obra está dividida em três capítulos organizados harmonicamente gerando uma nova percepção da pessoa de Jesus. O imaginário e imaginável são substituídos pelo imagético, Jesus é apresentado com uma aparência característica dos personagens do mangá, assim como todos os outros apresentados, e, inserido na realidade humana, produz uma nova significação. No fato de se produzir a obra em mangá há uma clara intenção em mudar a maneira que a mensagem vem sendo recebida, ou seja, exclusivamente verbal e religiosa. A recepção deixa de ser a religiosa tradicional, exclusivista, dogmática, e pode passar a recepção da mensagem de um ser humano universal, um da humanidade, portador de uma mensagem transformadora do ser e do meio em que se vive, sem violência e sem associação aos sistemas religiosos ou políticos.

Considerando a extensão da obra uma análise mais detalhada é possível a partir de um recorte e a narrativa das parábolas permite este recorte. Reunidas no seguimento 12 , dez parábolas são vivamente recriadas e conduzem o leitor em uma nova experiência. As autoras estabelecem a ordem narrativa a partir de Mateus e acrescentam parábolas contidas em Marcos, recriando o final da perícope por meio 
da inserção da travessia do mar da Galileia, deste modo o contexto é unificado, pois o início também se dá no mesmo local.

As parábolas são histórias dentro de uma narrativa maior. $\mathrm{O}$ ouvinte era convidado a imaginar a partir de imagens presentes na vida cotidiana. Deste modo uma parábola sobre semeadura, por exemplo, criava um imaginário imediatamente. O mangá recria a parábola dando vida a cada elemento, as sementes são vistas, o que ocorre com cada uma delas, deste modo um novo código semiótico é gerado que permite novas ressignificações. Ainda em relação às parábolas, o Mangá Messias faz de quatro parábolas, a da semente de mostarda, a do tesouro escondido, a da pérola preciosa e da rede de pesca, um quadro sinótico, onde Jesus no centro se insere em cada uma delas como aquele que representa o reino dos céus.

Observando somente as capas dos volumes, o leitor não consegue perceber que o conteúdo é bíblico, mesmo com o título, pois a maioria deles não têm referência bíblica, com exceção do termo "Messias", embora ele não seja exclusivo da religião cristã. Somente quando a leitura começa, verifica-se que são as histórias bíblicas sendo contadas em forma de mangá. A exemplo dessa capa do Mangá Metamorfose que trata do crescimento da igreja cristã após a morte de Cristo. Na capa tem alguns personagens que podemos chamar de época, mas não é possível identifica-los como bíblicos. Nesse como nos outros volumes tem uma pergunta provocativa sobre o tema. Nesse caso a pergunta é: "O mundo está acabando ou

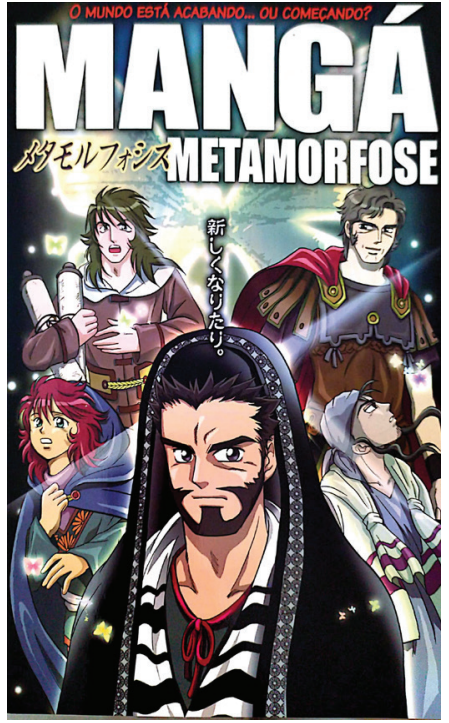

Figura 3 começando?"

Podemos observar também por intermédio das ilustrações que assim como em outras formas de arte, os autores colocam suas interpretações e pontos de vista, podendo até banalizar o sagrado do texto. A imagem abaixo é um exemplo disso, 


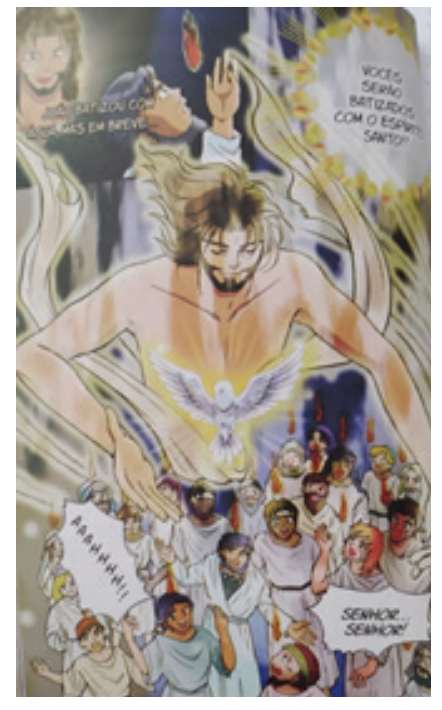

Figura 4

a ilustração é uma interpretação de como teria sido o evento sobrenatural, descida do Espírito Santo.

Outro ponto que chama a atenção é a inclusão por parte dos roteiristas da linguagem coloquial atual fazendo parte das histórias bíblicas, tornando ainda mais acessível e atraente o conteúdo bíblico de anos atrás a uma linguagem de fácil entendimento nos dias de hoje. O que mais uma vez pode comprometer o estilo religioso, tal qual descreve Tillich. Exemplos disso estão nos quadros abaixo. Na primeira figura, um apóstolo dizendo para Pedro: "Os guardas vão cair em cima!". Na segunda figura, Mateus dizendo para si mesmo: "Me engana que eu gosto".
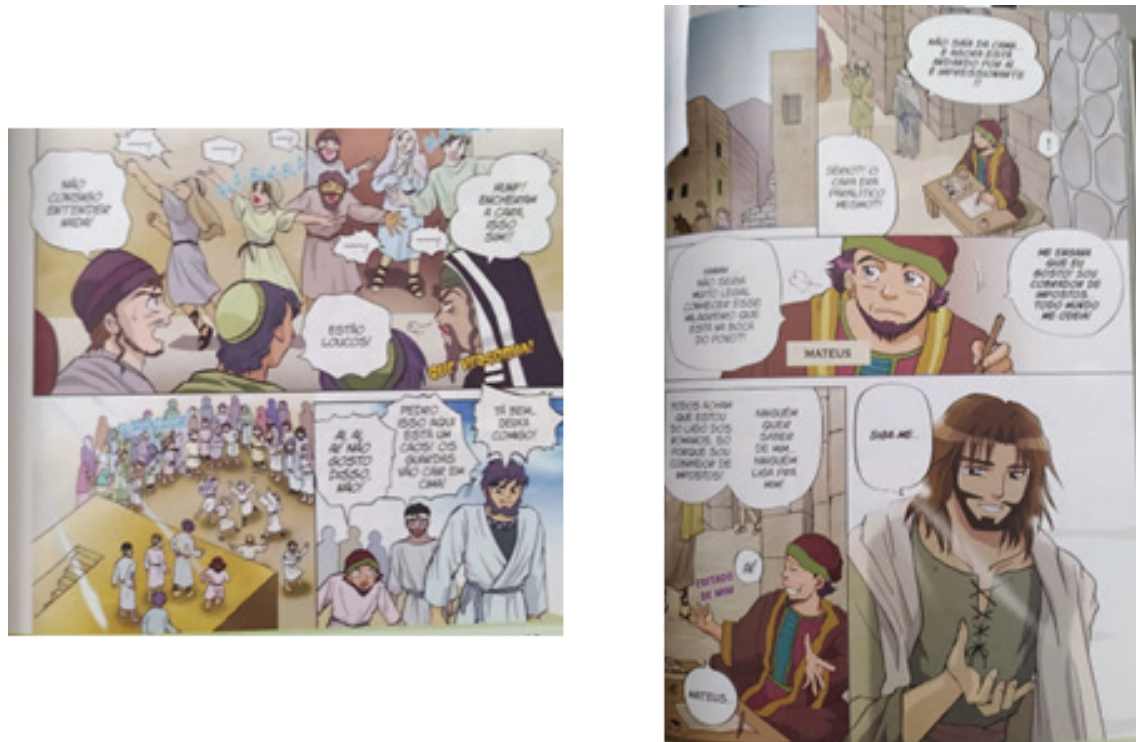

Figuras 5 e 6 
Além da linguagem coloquial, um componente comum a mangás que também foi utilizado nessa coleção foi o emprego das onomatopeias e linhas de direção, enriquecendo o texto e completando a cena com sons e movimento, o que não se consegue nas leituras dos textos bíblicos somente. Os quadros a seguir são exemplos disso:
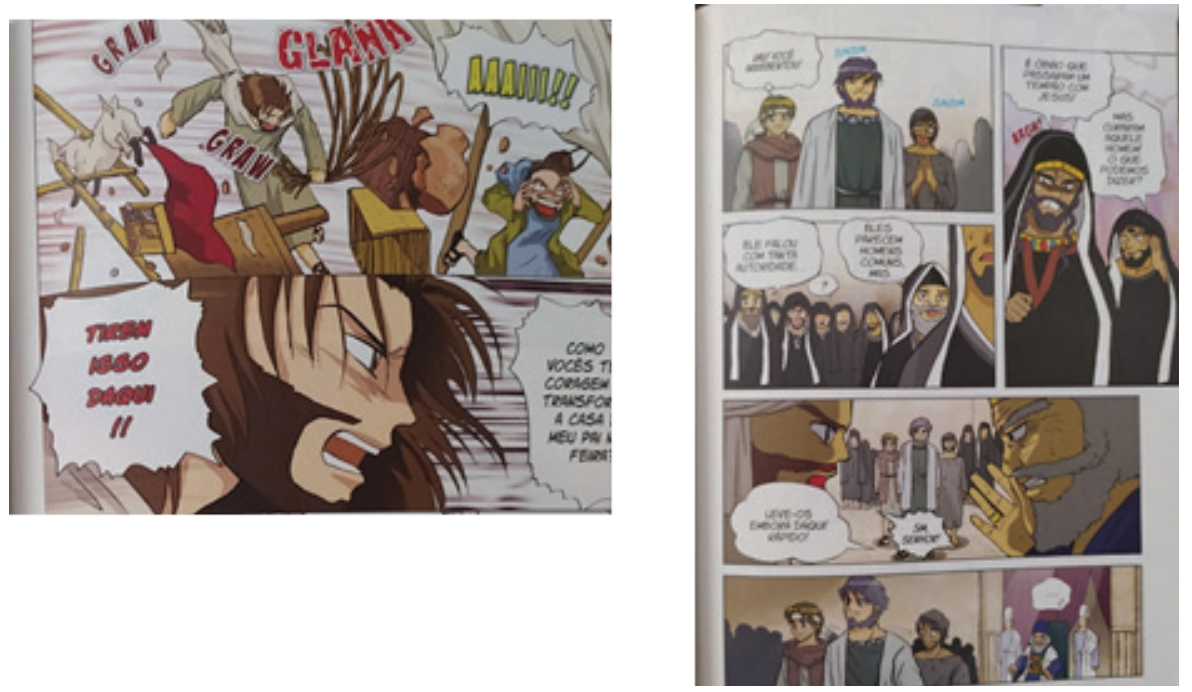

\section{Figuras 7 e 8}

Tillich sempre achou que o conteúdo era a dimensão mais importante da obra. Conteúdo significa aquilo que a obra contém. Supõe-se que o conteúdo esteja "dentro" dela. Neste caso, não há nenhum demérito na forma, desde que ela expresse um conteúdo e estilo religioso. Nesse sentido, Tillich mostrou-se ideologicamente comprometido com a religião e se mostrou totalitário, submetendo a ela a cultura com todas as suas expressões (Maraschin, 2003, p.75). Todavia, seus últimos trabalhos ultrapassaram barreiras, mostrando principalmente o valor dos estilos e conteúdos religiosos presentes em outras tradições religiosas, "oscilando entre a ingenuidade e a lucidez, (...) e uma grande abertura ao diálogo macro-ecumênico" (Calvani, 2004, p.47). O Mangá possui características peculiares que podem ultrapassar os limites missiológicos e trazer beleza e leveza às religiões ao invés de só mudar as formas. 


\section{Considerações finais}

O que se buscou no primeiro momento foi uma tentativa de transposição dos níveis de relação entre religião e arte no pensamento tillichiano para análise de uma arte digamos relegada como inferior em seu tempo, mas que com o passar dos anos teve o seu devido reconhecimento e passou desde então a ser considerada nona arte.

A partir da aproximação histórica de como o cristianismo representou iconograficamente seus textos sagrados e tendo como lugar de chegada a obra da NEXT, apresentamos o movimento de chegada da iconografia cristã ao oriente e de como o oriente, especificamente a arte do mangá japonês, recria parte da literatura cristã com beleza, leveza e originalidade, proporcionando um olhar para além dos dogmatismos e clausuras religiosas.

Após essa apresentação histórica foi feita uma análise da série NEXT Mangá, com alguns recortes, e as possibilidades de relação e identificação do tema e do estilo religioso presentes. Chegou-se à conclusão de que esse tipo específico de arte, Mangá, representado pela série NEXT apresenta tema não religioso e estilo religioso, com algumas ressalvas. O caráter missiológico ambíguo da obra, carregado de intencionalidades pode ser uma grande barreira à avaliação de Tillich, principalmente pela sua grande abertura ao diálogo macro-ecumênico. A função de uma obra de arte com ou sem tema religioso, mas carregada de estilo religioso não é um mero conversionismo, mas um despertar para o Novo Ser. Nesse sentido, a arte não deve prescindir do diálogo com outras expressões religiosas.

\section{Referências bibliográficas:}

ABRÃO, Daniel; GOMES, Nataniel dos Santos. Quadrinhos: arte contemporânea? Cadernos CESPUC de Pesquisa Série Ensaios, v. 2, n. 25, p. 213225, 2014.

BAUMER, Cristoph. The church of the east - An ilustred history of Assyrian Christianity. London: I.B. Tauris. 2016.

CALVANI, Carlos Eduardo. In MARASCHIN, Jaci (Org.) Paul Tillich: aspectos biográficos, referenciais teóricos e desafios teológicos. Revista Estudos da Religião. Vol 10: Paul Tillich 30 Anos depois. São Bernardo do Campo: Edims, 1995. 
. Teologia e MPB. São Bernardo do Campo: Loyola, UMESP, 1998.

. Momentos de beleza-Teologia e MPB a partir de Tillich. Correlatio, v. 4 , n. 8 , p. $38-57,2005$.

. Transformação, testemunho e diálogo: reflexões missiológicas a partir de Tillich. Estudos teológicos, v. 46, n. 2, p. 113-142, 2006.

DA SILVA, Antonio Almeida Rodrigues. Experiência estética versus experiência religiosa: anotações a partir dos estudos tillichianos sobre as artes plásticas. Correlatio, v. 7, n. 13, p. 75-94, 2008.

HQs e mangás: o quente em Frankfurt. Disponível em: https://www.dw.com/ pt-br/hqs-e-mang $\%$ C3\%A1s-o-quente-em-frankfurt/a-654090. Acesso em: 20 nov. 2020

PALMER, Martin. The Jesus Sutras: rediscovering the lost scrolls of Taoism Christianity. New York: The Ballantine Publishing Group. 2001.

MARASCHIN, Jaci Correia. Relações entre arte e corpo no Brasil. Correlatio, v. 2, n. 3, p. 69-86, 2003.

Rare Christian Painting from Late 16th Century on Display. 2018. Disponível em: Rare Christian Painting from Late 16th Century on Display| Nippon. com. Acesso em:

RODRIGUES, Luís Alexandre. Caminho Doloroso. As gravuras italianas da Ordem Terceira de Vinhais, 2013. Disponível em: https://www.cepese.pt/portal/pt/ publicacoes/obras/os-franciscanos-no-mundo-portugues-iii-o-legado-franciscano/ caminho-doloroso-as-gravuras-italianas-da-ordem-terceira-de-vinhais. Acesso em:

TILLICH, Paul. Existentialist aspects of modern art (1956). In: Main works/ hauptwerke. Berli/New York: de Gruyter/Evangelisches Verlagswerk, 1990. editores, 1974.

. Teología de la cultura y otros ensayos. Buenos Aires: Amorrortu

Submetido em: 4-8-2021

Aceito em: 3-9-2021 